\title{
Be Aware of Predatory/Fake Conferences!
}

\author{
Taner Kemal Erdağ (it) \\ Editorial \\ Department of Otorhinolaryngology, Dokuz Eylül University School of Medicine, İzmir, Turkey
}

ORCID ID of the author:

T.K.E. 0000-0001-5636-3343.

Cite this article as: Erdağ TK. Be Aware of Predatory/Fake Conferences!. Turk Arch Otorhinolaryngol 2019; 57(3): 111-2.

\section{Corresponding Author:} Taner Kemal Erdağ; taner.erdag@deu.edu.tr

Content of this journal is licensed under a Creative Commons Attribution 4.0 International License. Available online at www.turkarchotolaryngol.net
Scientific conferences are important activities in the lives of scholars. These conferences aim to gather important authorities, academicians and researchers of that field to exchange and share their novel research results, new ideas and experiences. They provide an interdisciplinary forum for researchers, practitioners and educators to present and discuss their recent studies. In these conferences it is possible to meet and communicate with leading scientists or look for research collaboration opportunities, developments and trends. These conferences also provide opportunity for the young academicians to gain experience in the presentations of original and unpublished results of conceptual, empirical or experimental work in their fields (1-3).

Scientific conference attendance and presenting at international ones is an important issue especially for young academics and researchers as it is also necessary for academic promotion in many countries (1).

In the last few years there is a remarkable trend for the organisation of international conferences, in particular multidisciplinary ones also in our country. While some of these conferences are legitimate, the number of suspicious organisations are not rare. Following the rapid dissemination of predatory journals and publishers all over the world, predatory/fake conferences are now a new danger for the academy (1-4).

Some aspects of these suspicious international multidisciplinary conferences are noteworthy. Usually their organisers are not well-known. Although they are named as multidisciplinary conferences, they are quite on irrelevant topics. It is not unusual to see many different fields of science like landscape architecture, naval architecture and marine engineering, agriculture and forestry and health sciences at the same time in these conferences (1, 2). The international scientific committee members are usually limited in number and from developing countries. Registration fees are arrenged not for participitation, but according to the number of oral presentations or posters. Similar to predatory journals, boring e-mails are sent soliciting conference abstract submissions or invitations to speak at these conferences by the organisers $(1,2)$.

Predatory/fake conferences are often organised by for-profit companies who abuse inexperienced but eager young academics and researchers to present for academic promotion, a well-known characteristic of predatory journals. While researchers pay to speak at these events, there is no concern for the content and quality of the abstracts or presentations for the conference organizers. So these conferences do not provide any benefit for the development of science (1-4). That's why universities, research institutions, Council of Higher Education and socities of medical specialities should take responsibility to educate young academics and researchers about the predatory/fake conferences and their dangers. They should also refuse to promote or provide funding to researchers attending these conferences $(1,4)$.

Unfortunately, there are also some academics or researchers who prefer achieving easy success. They can submit abstracts knowingly to these 
conferences and use them for academic promotion $(4,5)$. But it should not be forgotten that such attempts may cause problems for these people in their future academic lives as we all live in the internet age, where nothing stays secret.

\section{Reference}

1. Cobey KD, de Costa E Silva M, Mazzarello S, Stober C, Hutton B, Moher D, et al. Is this conference for real? Navigating presumed predatory Conference invitations.J Oncol Pract 2017; 13: 410-3. [CrossRef]
2. Asadi A, Rahbar N, Rezvani MJ, Asadi F. Fake/bogus conferences: Their features and some subtle ways to differentiate them from real ones. Sci Eng Ethics 2018; 24: 779-84. [CrossRef]

3. Sorooshian S. Conference wolves in sheep's clothing. Sci Eng Ethics 2017; 23: 1805-6. [CrossRef]

4. McCrostie J. Predatory conferences: a case of academic cannibalism. Int High Educ 2018; 93: 6-8. [CrossRef]

5. Rossiter RC, Stone TE. "Buyer Beware!" predatory conferences: Avoiding an expensive mistake. Nurs Health Sci 2016; 18: 414-5. [CrossRef] 